\title{
Legitimate Resistance through the Aesthetic
}

\author{
Hala Abu Taleb ${ }^{1 *}$, Al Rabiyeh ${ }^{2}$ \\ ${ }^{1}$ Department of English Language and Literature, The University of Jordan \\ ${ }^{2}$ Rasafa ST., Po box 950480, 11195 Amman, Jordan
}

Corresponding Author: Hala Abu Taleb, E-mail: Hala_abutaleb2002@yahoo.com

\section{ARTICLE INFO \\ Article history \\ Received: April 04, 2018 \\ Accepted: July 13, 2018 \\ Published: November 01, 2018 \\ Volume: 7 Issue: 6 \\ Advance access: September 2018}

Conflicts of interest: None

Funding: None

\begin{abstract}
Within the pragmatics of our conflicting world, few can deny peoples' right of resistance. It is true that those few are often the most powerful and thus the most influential when it comes to the international community and what qualifies as legitimate or illegitimate resistance. Nevertheless, resistance, in all its forms continues to disturb and challenge monolithic discourses and onedimensional perspectives. Among today's nations who directly suffer from such facts, Arabs and Muslims can simply top the list. Subjugated to almost daily international deformations and national manipulations, the "resistance" of these people heads the world's news, often as violent fighting of violent nations. If resistance defines a nation and its actions then defining resistance itself is a form of national consciousness and identity politics. That is how Arabs and Muslims should think of their resistance and its manifestations. We need to carry it on via shrewd strategies which maintain it civilized for the sake of our self-identification and keep it legitimate for the sake of our national cause. As we strive through our resistance, our unfortunate current image as terrorist and backwards should be an aim for reform rather than a justification for further dark connotations.
\end{abstract}

Key words: Resistance, Monolithic Discourses, National Manipulations, Self-Identification
Today, within the pragmatics of our conflicting world, few can deny peoples' right of resistance. It is true that those few are often the most powerful and thus the most influential when it comes to the international community and what qualifies as legitimate or illegitimate resistance. Nevertheless, resistance, in all its forms continues to disturb and challenge monolithic discourses and one-dimensional perspectives. Among today's nations who directly suffer from such facts, Arabs and Muslims can simply top the list. Subjugated to almost daily international deformations and national manipulations, the "resistance" of these people heads the world's news, often as violent fighting of violent nations. If resistance defines a nation and its actions then defining resistance itself is a form of national consciousness and identity politics. That is how Arabs and Muslims should think of their resistance and its manifestations. We need to carry it on via shrewd strategies which maintain it civilized for the sake of our self identification and keep it legitimate for the sake of our national cause. As we strive through our resistance, our unfortunate current image as terrorist and backwards should be an aim for reform rather than a justification for further dark connotations.

It is believed that strategies of resistance should never be formed in alienation of the strategies of control. As the later shifts the other should follow altering their forms, goals and mediums to assure effectiveness and perceptivity. This directly calls for different methods of fighting back through new channels that manipulate the systematic controlling of who and what is an Arab or Muslim. The aesthetic as both a political form and a resistance method offers not only a different medium of reaction but also a real chance for a different identity. In his book, T.V Reed explains that "It was far more likely that Black Panther Theater was embraced by the community in the sense that images of proud black men and women in black berets facing down cops gave evidence of a new kind of black person in the world, one who would not bow to racism any more." (Reed 2005, 54). Through the "theatricality" of the Black Panthers, the aesthetic inspired not only a form of civil disobedience but rather a new self definition through which African Americans sought a chance for a new birth and a fresh beginning. Through aesthetic attempts, many artists are tying to introduce a new kind of Arabs or Muslims capable once again to feel pride in the nation and its members and would no longer accept the limitations of their identities, potentials, and resistance.

\section{THE WAR OF ARTS VERSES THE ARTS OF WAR}

Wherever they might be found, resisting Arabs and Muslims seem to repeatedly fall within the global classifications of terrorism and fanatic extremism. Stigmatized as such, for legitimate or illegitimate reasons, the often rightful resistance of these people falls short within political spheres. 
The need for fresh resistance strategies is urgent especially as national events and issues increasingly prove themselves influential upon international times and spaces. With the political and economic upheavals that several Arab and Muslim countries experience, art and popular culture are prime candidates for the masses to express themselves and voice their dissatisfaction. Defying the elitist and politically complicated powers, popular culture can pass as the masses' politics, or the politics of the have-nots in opposition to that of the haves. Today, many artists in and outside the Arab and Islamic worlds are employing their talents to counter the political and cultural wars on their nations with the alternative wars of arts.

Various resistance forms are "... arising out of the feelings of injustice at being denied access or, worse, being misrepresented in the public sphere." (Rajgopal 2003, 51). Such public barring eventually juxtaposes the "poetic" with the "politic" turning the aesthetic into a battlefield. Thus, aesthetic resistance brings the public sphere into the picture as not only a sight of struggle but also a player. In modern times, the Mexican "muralista" art movement stands as a perfect example of art being a public tool of social emancipation and political involvement. Mexican muralism testifies on how art can stand out despite walls, segregation and silence as an apparatus for self representation, community collaboration and intercultural alliance. Chicanos' murals have a lot to teach Arabs and Muslims who already imitate this art on sights such as the Israeli's apartheid wall in the West Bank. Along that wall, national and international groups and individuals have left messages of resistance and refusal to the political reality of the wall and the occupation. The political weigh of these messages are believed to equal if not strategically surpass some militant forms of resistance. This is not to underestimate or even judge such resistance movements and organizations but rather it is to emphasize the strategic benefit of the aesthetic resistance of Arabs and Muslims in a time where their fighting back is judged as arising out of feelings of jealousy of others freedom, condemnation of others ways of life, and surely an inherited tendency toward violence and destruction. The graffiti and murals on the apartheid wall challenge the ugliness that Arabs and Muslims are often presented within as peoples unqualified for beauty or art.

Hence, this alternative kind of resistance functions along the same lines of traditional resistance in turning the objects into subjects through a channel that is peaceful in nature, political in context and confrontational with the space it occupies. This idea of space or "placing" is crucial for a nation or peoples who struggle daily to find a dignified place for themselves in their homelands, within their host communities or along the international discourses of justice and civilization. The irony represented in the opportunity of existence that a wall or any other sight offers is undeniable as silencing barriers sometimes make oppression more visible. And with art, while juxtaposing the political and ideological idea of such barriers, the subaltern can be made more vocal. Accordingly, the politics of aesthetic resistance call for civil disobedience against the placement or displacement of peoples within the historical discourses of the politic as well as the poetic.
Aesthetic productions of Arabs and Muslims reflect a realization of the role of beauty and art in the process of racial formation and identity deformation. Placing their resistance within today's image and visual representations carries their claims of injustice, misrepresentations, and identity deformation to a higher level of nonconformity "...that involves both "identity announcement" made by individuals claiming an identity and the "identity placement" made by others who endorse the claimed identity, and an identity is established when there is a "coincidence of placement and announcement." (Zhao et al. 2008, 1817).

\section{NATIONAL AESTHETICS: NATIONAL AND INTERNATIONAL INFLUENCE}

Resistance manifestations, global solidarities, and transnational aspirations form a solid foundation for a systematic political deconstruction of certain "realities" today as these realities are gradually being replaced by fresh defiant constructions. Arab and Muslim artists should comprehend the politics of the location they occupy as not only representatives of their nations but also members of an international community of artists and activists. Such a position eventually brings the national into the international fussing the global with the local. Through various aesthetic productions, artists can initiate a serious reform regarding the ways through which we define the private, politicize binary oppositions, and problematize nationalism. Realizing such a position renders Arab and Muslim artists responsible of a wider audience who is not only thirsty for the truth but also ready for building solidarities among the peoples rather than governments. Being part of the aesthetic community presents fresh horizons for Arabs and Muslims through which they can achieve a level of international inclusion and peaceful recognition.

Nevertheless, this is not a temptation to bargain Arabic or Islamic heritages for global acceptance and integration. Rather, it is a call for a progressive resistance that speaks to the politics as well as realities of our times and spaces. It is a call for utilizing the medium itself, in this case art, as the message; Arabs and Muslims as diverse nations with alternative ways or resistance. If the majority of the Arab and Muslim people are aware of the systematic generalizations about who and what they are and such generalizations are often connotations of violence, backwardness, and ugliness, then art might offer a different lens through which the world can re-define or at least re-consider who or what is an Arab or Muslim. Unfortunately, within Third World countries art is often left behind as the people fight for daily bread or shelter for their families. Popular culture itself is not accessible to everybody since it is directly affected by the economic, political and cultural calculations. Nonetheless, the aesthetic resistance is noticeably increasing within these communities. For example, Egypt is among the leading Arab countries in producing various forms of popular culture yet among the most crowded and poorest. Recent Egyptian movies present new frames within which daring subject matters are being delivered to the audience. Such topics are not alien to the Arab and Muslim realities rather they are just continually 
shoveled under the carpet as threats to the rigid cultural and religious ways.

Considering the advantageous overlapping of national and international aesthetics, it is important to acknowledge the role of the Diaspora as national reformers and international activists. While art clearly knows no geographical or political boundaries, the Arab and Muslim diaspora are making use of the international opportunities to nurture their craft and send their message not only to international communities but also to their local ones. The universal domain of the aesthetic offers a relatively safer and more professional environment for Arab and Muslim diaspora compared to the limitations and censoring these artists might face within their national realm. Often, such artistic productions are critical forms of visible patriotism that roots artists deep in their homelands, while maintaining their links with the host countries. The establishment of this dual identity is sure to gain legitimacy with the locals who appreciate the sense of belonging as well as with all others who identify with the "outplaceness" and the loyalty to host countries. Thus, any production that is critical in nature can be appreciated as patriotic rather than a threat to any given national security or way of life.

Using what is international to reach the national bridges the gap between peoples who otherwise often observe each other as different and aliens within mainstream media and discourses. Clearly, popular culture produced by Arab and Muslim artists carries a lot of political undertones justified by their realities and locations within today's world. Many relate to Arab and Islamic occupied lands, deformed identities, and "terrorism." In recent cinematic works such as Paradise Now and Salt of this Sea the Middle Eastern political scene is dominant and is presented within a context of what is really going on within the region's actual times and spaces. Both movies track the daily lives of normal people with normal aspirations yet with on major challenge; their Arabic and Islamic identities. The political then is not imposed on the aesthetic scenario but rather a consequence of it. Unlike other foreign or western movies, the focus is not how to vilify these people through highlighting their violent choices but rather how to problematize these choices as true free choices or ones imposed on them. In both movies, the audience is introduced to a character with a hyphenated identity as Arab but yet western. Such notion underlines the connection between Arab diaspora and locals on one hand and Arabs in general and any other nation on the other. These characters offer the alternative ideology and thus politically emphasize the relation between East and West as well as aesthetically highlight the diversity within the Arab or Muslim nations.

Other recognized visual works that are mainly produced and circulated within the digital sphere, include works such as Planet of Arabs, Forbidden Love and Reel Bad Arabs which complicate the simple equation of Arabs and Muslims as being equivalencies to each other or to the politics ruling their realities. Again the aesthetic messages are what rule here rather than the political connotations. The images of these Arabs or Muslims are presented within a general atmosphere of refusal to injustice as well as aspiration for a better future and intercultural solidarities. The increasing influence and exposure of the Arab and Islamic masses to the outside world through various methods, mainly aesthetic ones, leaves the door open for change and hope. Within the same logic, it restores the authenticity of these nations as ones capable of producing beauty and long-lasting images. Like any other nation who strives to fight negative stereotypes, the Arabs and Muslims welcome the opportunities of presenting themselves to the world not as the world already knows them but rather as they know themselves. Popular culture and aesthetic resistance should not be seen as a feeble way out for a nation who really has no other choice and thus be judged as cowardice or conformity. It is rather our right and truthful identity as nations long associated with art and beauty and for long victimized by them.

\section{NATIONALISTS AND BEAUTIFUL: REFURBISHING WHAT IS OURS}

Seeking hope in what is ours and reclaiming our position within the aesthetic spectacle is not only a form of resistance but a long-waited political need. Such alternatives are urgently due today as young generations desperately seek role models to whom they can look up and draw pride from. The time is now to replace the images of extremist Muslims, corrupted Arabs and their exotic women with those of the many artists who have the ability and will to inflect change and hope. And this no dream for us as many artists and other influential figures are already paving the way for self representations, transnational appreciation and eventually intercultural communication.

A personal favorite and one of today's rising artists is the Arab-American Suheir Hammad. A Muslim of Palestinian descent, Hammad is popular as a poet, author and political activist. Living as refugees in Jordan, her parents decided to move to the US when she was five years old. Often, her works reflect this sense of displacement, identity in-betweenness in addition to the political, cultural and gender inequalities and misrepresentations of both eastern and western cultures. Her aesthetic identity crosses with her ethnic one establishing a political connection with African American Hip-Hop. This artistic collaboration emphasizes the role of art as an international tool of protest capable of merging the privacies of cultures with the public sphere of activism and politics. "First Write Since", her poetic reaction to $9 / 11$, is among her most famous works within the Arab and Muslim diasporas and locals through which she frames the political events of what appeared to be a national tragedy within the cultural and political otherness of Arabs and Muslims. Her other works include her books Born Palestinian, Born Black, Drops of this Story and Breaking Poems. She also has play production and film experiences, the latest being her role in the movie Salt of This Sea (2008).

The identities and political stances negotiated through Hammad's works are part of a global message against injustice and otherness. Mediated through the aesthetic, Suheir's voice is smooth, appealing, tolerant and yet a very strong one. As a female, Hammad stands in defiance to the images and myths haunting Arab and Muslim women as being op- 
pressed, silenced and eschewed from public life. Hammad's live performances, which are recorded and highly circulated via the Internet, offer a chance to see and hear an Arab Muslim speaking out bravely, being politically correct and aesthetically appealing. The beauty of her works removes the political veil of otherness and estrangement from upon the true faces of Arab and Muslim men and women. Her poetry, such as in ZaatarDiva collection, is a good example of alternative Arab and Muslim voices and faces through which one witnesses a rich diversity and multiple identities as opposing to the more often monolithic representations. Her performances evoke hope in a better common future represented by politically and culturally sophisticated figures capable of declaring the position of their nations within the sphere of what is beautiful and civilized.

The defiance that Arab or Muslim female artists show against their deformed images is matched by their male equals. Today, the Muslim and Arab worlds and diasporas identify with the identity of Sami Yusuf more than they do so with his messages. A British-Muslim of Azeri descent and mastery in Arabic language, Yusuf prefers to mediate his musical messages through English in order to guarantee a wider influence. Like many Muslims today who are juggling between two identities or more, two languages or more and tow "homes" or more, Yusuf as an image seems closer to the reality and identity of many young Muslims. He is not only a good singer but rather a political identity that many wish to see prevail over the many deformations existing today. Maintaining a modern, stylish look while still being a devoted and very spiritual Muslim, the very presence and appearance of Yusuf defies many of the stereotypes promoting Muslims as ugly, shaggy and dirty. The artist is also highly educated and politically vocal either through his music or interviews.

The political message in the visual tracks and the use of many tongues in his works is particularly important in a time where Islamic discourses are represented as so aesthetically rigid and culturally inflexible. Often, the young and "hip" Yusuf is featured in his videos practicing a normal life, in various geopolitical contexts, and among a wide array of different people. Islam, Muslims and the Arabic within his works are shrewdly situated along a fresh and progressive aesthetic politics that manages to present them all as advocates of love, tolerance, and beauty. Yusuf's popularity is definitely not limited to the Arab and Muslim world, yet he is featured performing in Western mainstream media. As in the case of Hammad, witnessing these artists actually speaking out and using Arabic within beautiful and political contexts can definitely alter the dark images and concepts haunting these people and their language.

One cannot help but wonder what level of political complication would the neatly bearded Yusuf or the trendy Hammad bring to the western and eastern spectacle? What if audiences get the chance to hear the Arabic and Islamic phrases uttered by the musical vocals of Hammad or Yusuf every time they hear the words of our times' most famous "Islamic" extremists and fanatics! What is beautiful and aesthetic is capable of altering stereotypes as well as opening windows for global associations and collaborations. The Mexican-American border, the Berlin Wall and the Israeli apartheid wall all line up for artists and activists as a shared metaphor for shared sufferings of dehumanization and deformations.

The counter discourses offered by such scenes are clearly cross-cultural and the notion of unity they inspire is indisputable. Generally, popular culture paths the way in front of the various efforts aiming to establish a community of artists that surpasses borders. Some Muslim African-Americans are examples of such artists who combine within their aesthetic messages distinctive identities and ideas that are often observed as contradictory and juxtaposing each other. Such artists are juggling their African identities with their Americanism, their Islamic ideologies with their non-Muslim audiences, and their western affiliations with their eastern heritage. Resisting discourses and images which reject such combinations appears to be the domain of Islamic Hip-Hop artists who depend on the beauty of the aesthetic to restore the beauty of their cultural and religious identities. While regarding the American-oriented genre, these Islamic rappers are trying to restore their political positions as American citizens as well as American-Muslims in opposition to the Arab Muslims.

American male and female rappers touch upon many crucial issues within the American society as well as the international community. Female artists such as Miss Undastood, Jamila, and Ms. Latifah defy not only the images of Muslims as incapable of aesthetic communication, but also the gender politics of both Hip Hop and the American culture. The works of many of these artists are collected electronically on the Muslim Hip Hop.com website. ${ }^{1}$ According to the website, the mission is to highlight the creative ways for Muslims in expressing their frustrations and aspirations. The political correctness of Islamic Hip Hop speaks out against the injustices committed against Muslims and those committed by them. The exquisiteness of the method along with objective messages stand as evidence of beauty, creativity and civilization regarding the methodology and ideology of nations repeatedly deprived of their right in such domains.

While imperialism, national corruption and wars cut through the Middle East like probably no other place today, the war of art persists as an alternative attracting less exhausted members and creating fewer wounds. As deformed images of bad Arabs and Muslims haunt western realities they also distress the eastern masses. Feared within their own lands, many Arabs and Muslims share with diasporic artists the dream of employing the aesthetic to bring about political reforms and defy corruption. As most of these local works are produced in Arabic, the international domain is still reluctant to embrace them. Nevertheless, aesthetic collaboration with other international professionals paves the way for the manifestation of international existence and resistance.

One good example is the collaboration between the Iraqi singer Kazem Al-Saher and American artist Laura Poitras through her documentary My Country, My Country, which was nominated for an Academy Award for Best Documenta- 
ry Feature (2007). As Poitras takes her audience through the daily lives of Iraqis under the American occupation, Al-Saher composes the music that introduces the spirit of the sufferings, longings and hopes. It is probably a cliché to try to highlight the political message behind the coming together of an American and an Iraqi through a peaceful work yet it is unavoidable. Al-Saher has other collaborations with many other international artists including Lenny Kravitz, Sarah Brightman, and Quincy Jones. Particularly, Al-Saher's experience has influenced many Arab artists who are seeking to situate their works, identities and communities within the political message of aesthetic resistance, whether on the national or international levels.

The aesthetic and the political goals seem to often overlap. The time is now to produce high quality works capable of overcoming the limited nationalisms of the Arab and Muslim worlds and the geopolitical boundaries of the globe. Our experiences are similar to those of many other political artists and global movements who utilize the relatively safe haven of art to re-visit places, faces and missed opportunities. The global history of alternative resistance is there for those ready to take their resistance to a higher level and mobilize the masses through beauty as opposed to destruction. Arab and Muslim artists such as Majeda Al Romi, Omar Khairet, and Julia Boutros are turning national songs and eastern music into some kind of a civil religion that evokes the feelings of a national cause, the need for change, and the urge to restore their international identities. In the face of political crises and excessive otherness and fear, aesthetic solidarity stands a good chance in gracefully exposing the common global oppression and struggle and uniting the masses around a common goal of coexistence.

\section{AESTHETIC RESISTANCE AND THE VISUAL SPECTACLE}

Currently, mainstream media enjoy a great level of power and authority over our lives leaving us paralyzed, too scared to search for the truth or too lazy to even think it exists. With daily news, T.V shows, and flourishing cinematic business, the visual spectacle rarely appears multi-cultural or multi-political. Increasingly, the visual deepens its roots within the Middle Eastern consciousness of political resistance especially as video art becomes "one of the major artistic media in the entire Middle Eastern region over the past ten years" (Bank 2008, 18). The visual arts produced today, specifically videos, regardless of their quality offer a way out of the relative strictness and professionalism of established visual productions. The fresh, more "common" aesthetic works free their messages from confinement to certain historical moments, whether they are cultural or political.

Works like Poster, Bethlehem Bandolero, Chic Point and Girl with forty braids are examples of these new alternative techniques of inside resistance to cultural inflexibilities, gender inequalities, and political corruption. As these works and many others provoke reflection on the national actualities, they are still perceived as the initial political mobilization to confront the international deformations. The inevitable connection between here and there is often clearer in the works of the diasporic bodies. The advantage of being an outsider and an insider at the same time equips these artists with the political knowledge, aesthetic skills, and contextual correctness that allow for the productions of successful transnational works. The audiences addressed by such works are culturally, politically and linguistically international. Their self-representations is often a claim of their rights and responsibilities as in-between political bodies, facing the consequences of actions and ideologies carried on by some in their home countries or in their host ones, and directed against their fellow citizens in both contexts.

Digitalization takes the political and aesthetic visuals to a further level of expression. Any picture, home video, or short film can easily be uploaded to the World Wide Web and within seconds it claims its position within international virtual reality. Definitely, this advantage is used both ways, as a resistance act and as a hegemonic one. Yet, the fact that people can reach out to each other is undeniably appealing. The visual offers a communication vent for subalterns who are either framed by the political spectacle or demeaned by aesthetic works. Addressing audiences with a medium they are familiar with probably guarantees mutual understanding.

One Nation, a website sponsoring artistic video works, is probably one of the comprehensive electronic entities digitally existing today. The website identifies itself as "a philanthropic collaborative with the vision of fostering a national conversation about the common values we share as Americans, regardless of how we choose to express our spirituality."2 One Nation, Many Voices is the online film contest to which One Nation attracts a variety of artists of different races and ethnicities. Many Muslim artists participate and contribute to the well-being of their countries and communities. Through such public existence, Islam is successfully represented as a rainbow of faces, voices and alternatives. Inclusion, acceptance, and a relatively democratic space is what bring these voices together as Muslims, but most importantly as artists who long for a better international community.

The aesthetic quality and influence of these works is fortified by real-life experiences and tangible pains and deconstruction. At one point, these short films manage to recapitulate many of the cultural and political hegemonic ideologies that hinder social mobility and political activism. The year 2009 included works such as Arab in America, A Good Question, and America: Lost in Translation and many others which utilize tolerance, patriotism and beauty as a counter method to mainstream's otherness and divisions. Today, many electronic productions and techniques challenge the bi-polar notions of here and there, us and them, and Self and Other. Such fresh venues function as a "pass" not necessarily for bodies but surely for ideologies, aspirations and identities that are eager to reach out for others beyond the geographical boundaries, phenotypes and political deformations.

Such optimism should never elude us from acknowledging the very real existence of the digital divide that is silencing many, whether politically or culturally. Likewise, we must emphasize the rightness of "I link, therefore, I am" (Hafner 1999). Thus, dismissing the increasing political in- 
fluence of the World Wide Web through the argument of its incomprehensiveness sounds useless for the cause of Arabs and Muslims. Influencing the virtual domain should be a priority for those artists and activists who wish to alter the general and more physical spectacle today. One only needs to type the word Arab or Muslim in any search engine to realize the kind of the images, videos, cartoons and faces which represent those groups of people online. It should not be satisfactory to know that a good deal of these productions get dismissed as "low culture" as the core issue here is not justice through classifications but rather justice through representations. Among many nations, the Arabs or Muslims should know better that justice is not going to come knocking at their doors; they have to snatch it. Aesthetic efforts should consider the virtual as a prosperous domain for the translation of the cultural and political dimensions of nations.

The same logic that highlights the importance of Arabs' and Muslims' existence in virtual reality emphasizes the urge to exist in physical visual reality. The aesthetic continuation of Arabs and Muslims as actors and actresses who are part of westerners' daily leisure time is very significant. Being included within the mainstream media as "normal" people, Arabs and Muslims have a chance to place their national identities as political subjects. Such inclusions juxtapose many other political discourses and texts through which Arabs and Muslims are often unwillingly represented or misrepresented for that matter. The politics behind such existence is to present a common face and a day-to-day experience of real people, who deal with real wounds and challenges. Works like the Canadian sitcom Little Mosque on the Prairie are productions that stand out as a grassroots' political rejection of elitist political craziness. Created by a Muslim British-Canadian, Zarqa Nawaz, the show tackles some of the cultural, racial and political challenges facing Muslims today. Humor is the show's best aspect in addition to the objective depictions of the characters that belong to various races, ethnicities, religions as well as generations.

The familiar and more "homey" nature of TV sitcoms competes with the more expensive and elevated levels of cinematic productions. The fight for amending the damage done to the identities of Arabs and Muslims through visual images is surely a patriotic action that is targeting the wider international audience. Currently, many Arab and Muslim filmmakers are claiming their aesthetic and political position within the international cinematic profession. Struggling against an established, ready-made historical body of stereotypes, in addition to political, cultural and industrial limitations, the mission does not seem easy.

Hani Abu Assad's 2005 movie Paradise Now stands as probably the most renowned due to its controversial story and the fact that it was the first Palestinian film to be nominated for the Academy Awards (2006). Being recognized internationally, and included in many prestigious film festivals is a political achievement towards evoking an international recognition of Arabs' and Muslims' identities and realities. Nevertheless, presenting their identities and nations to the world is as challenging as re-representing their true faces and voices to the Arabs and Muslims masses and locals. Films such as Captain Abu Raed (2007) and Salt of This Sea (2008) are recent examples of this alternative presentation of who and what are Arabs and Muslims. It is through efforts like these that we can encounter the ever-prevailing culture of fear that cuts through our hearts and minds.

\section{CONCLUSION}

Artists dig their roots elsewhere away from corrupted leaderships, cultural and religious infelicity as well as international ugliness. The political method of art seems to depend heavily on life and existence rather than death and extinction. Thus, aesthetic resistance of nations is a patriotic obligation that is likely to promote the need for social and political freedoms. Time is due for Arabs and Muslims to shed away the role of the victims that has kept them politically and culturally crippled, paralyzed in times and spaces that continue to leave them behind as the world moves on. Just as the deformed images are no longer accepted or tolerated so is Arab's and Muslim's silence, whether it is silence against the harm done to them or silence against the harm done by few of them

Postcolonial film theorist Ella Shohat explains that "cinematic counter-telling" has actually been implemented since the past-World War II collapse of the European empire (Rajgopal 2003, 63). Shedding the legacy of colonialism and imperialism is not achieved through military and political manifestations alone. The stories have to be heard, the faces need to be seen, and the identities are ready to be reconstructed by those who suffered most and still suffer the wounds of deformation and subjugation. Aesthetic counter-telling is a cultural claim through which artists negotiate new forms of existence, nationalisms, and identities. The aesthetic and political countering to the empirical "truth" and history is a right for the colonized, the subalterns, and suppressed nations. Today, we all should realize that in the war of arts the battlefield is as dangerous as that of a real war, and a moment of desertion might be fatal.

\section{END NOTES}

1 http://www.muslimhiphop.com/

2 http://www.onenationforall.org/

\section{REFERENCES}

Bank, C. (2008). "Veiled Visibility: Video Art in Syria." International Institute for the study of Islam in the modern world review, 22, 18-19.

Hafner, K. (1999). "I Link Therefore I Am: A Web Intellectual's Diary." New York Times, July 22.

Naber, N. (2000). "Ambiguous insiders: an investigation of Arab American invisibility." Ethnic and Racial Studies, 23(1), 37-61.

Rajgopal, Sh. S. (2003). "The politics of location: Ethnic identity and cultural conflict in the cinema of the South Asian Diaspora." Journal of Communication Inquiry, 27(1). 
Reed, T.V. (2005). The Art of Protest: Culture and Activism from the Civil Rights Movement to the Streets of Seattle. Minneapolis: University of Minnesota Press.

Said, E. (1979). Oreintalism. 25 ${ }^{\text {th }}$ Anniversary ed. New York: Vintage Books.

Semmerling, T.J. (2006). "Evil” Arabs in American popular film: Orientalist fear. Austin: University of Texas Press.

Shaheen, J. (1984). The TV Arab. Ohio: Bowling Green State University Popular Press.
. (2000). "Hollywood's Muslim Arabs." The Muslim World, Spring, 90(1/2). . (2001). Reel Bad Arabs: How Hollywood vilifies a people. New York: Olive Branch Press.

Sisler, V. (2008). "Digital Arabs: Representation in video games." European Journal of Cultural Studies, 11(2).

Zhao, Sh., Sherri, G., and Jason, M. (2008). "Identity construction on Facebook: Digital empowerment in anchored relationships." Computer in Human Behavior, 24(5). 